\title{
Propriedades do aço AISI 4140 nitretado a gás
}

\author{
Properties of gas nitrided AISI 4140 \\ steel grade
}

Igor Luis Diehl ${ }^{1}$, Juan Dong ${ }^{2}$, Alexandre da Silva Rocha ${ }^{1}$

\author{
${ }^{1}$ Laboratório de Transformação Mecânica - LdTM - PPGE3M/UFRGS CP: 15021 - 91501-970, Porto Alegre, RS \\ e-mail:diehl@ufrgs.br \\ ${ }^{2}$ Stiftung Institut für Werkstofftechnik IWT, Badgasteiner Strasse 3, 28359, Bremen, Alemanha \\ e-mail: dong@iwt-bremen.de; alexandre.rocha@ufrgs.br
}

\begin{abstract}
RESUMO
Nitretação está entre os tratamentos superficiais mais efetivos. Os principais benefícios da nitretação aos aços são o aumento da dureza, resistência ao desgaste, resistência à fadiga e resistência à corrosão. Com isso, este trabalho tem por objetivo avaliar a resposta do AISI 4140 a diferentes condições de nitretação, quanto às propriedades químicas, microestruturais, de dureza e propriedades tribológicas. Para isso, foram feitas análises metalográficas, espectroscopia de emissão óptica de descarga incandescente (GDOES), difração de raios-x, microdureza e ensaio pino-sobre-disco. Nitretações gasosas foram executas em duas diferentes condições, com potenciais de nitretação de 0,6 e 2,0. A duração dos tratamentos foi de duas, quatro e seis horas. Adicionalmente, foi realizado um tratamento de nitrocarbonetação de seis horas, com a adição de carbono via injeção de gás de $\mathrm{CO}_{2}$, com potencial de carbonetação de 1,0. Os resultados mostraram a formação de camada branca seguida de uma camada de difusão com gradiente de propriedades como dureza e composição química. Um aumento significativo de dureza de 400 HV é observado na camada de difusão. Os diferentes tratamentos mostraram que o potencial de nitretação tem maior influência sobre a espessura do que o tempo de tratamento. A nitrocarbonetação formou uma camada nitretada $21 \%$ menos espessa do que nas amostras nitretadas de mesmo potencial de nitretação, enquanto que a camada de poros foi semelhante. Nos testes tribológicos realizados, houve uma diminuição do desgaste de $61 \%$ com a presença da camada nitretada e o modo de desgaste mudou de abrasivo/adesivo para abrasivo.
\end{abstract}

Palavras-chave: Nitretação gasosa, aço AISI 4140, pino-sobre-disco, difração de raios-x, GDOS.

\begin{abstract}
Nitriding is among the most effective surface treatments. The main benefits of nitriding on steels are the increasing in hardness, wear resistance, fatigue resistance and corrosion resistance. Therefore, this study aims to evaluate the response of AISI 4140 to different nitriding conditions, regarding chemical, microstructure, hardness and tribological properties. To accomplish this, metallographic analyzes, optical emission spectroscopy glow discharge (GDOES), x-ray diffraction, hardness and pin-on-disc test were performed. Gaseous nitriding were performed in two different conditions, with nitriding potential of 0.6 and 2.0. The process time was two, four and six hours. Additionally, a nitrocarburizing treatment was carried out with the addition of carbon via $\mathrm{CO} 2$ gas injection with carburizing potential of 1.0. The results showed the formation of white layer followed by a diffusion layer with gradient properties as hardness and chemical composition. A significant increase in hardness about $400 \mathrm{HV}$ is observed in the diffusion. The different treatments showed that the nitriding potential have more influence on the thickness than the treatment time. The nitrocarburized sample formed a nitrided layer $21 \%$ less thick than the nitrided sample with same nitriding potential, while the pore layer was similar. In performed tribological tests, there was a $61 \%$ decrease in wear due to the presence of the nitrided and the wear mode changed from abrasive / adhesive to abrasive mode.
\end{abstract}

Keywords: Gas nitriding, AISI 4140 steel grade, pin-on-disc, x-ray diffraction, GDOS. 


\section{INTRODUÇÃO}

Dentre os principais e mais efetivos tratamentos para a melhoria das propriedades superficiais de aços, encontram-se a nitretação e a nitrocarbonetação [1]. Estes são considerados processos termoquímicos, onde o nitrogênio e/ou carbono atômico é difundido através da superfície do material e produz um aumento significativo das propriedades mecânicas da superfície da peça. Entre os benefícios da nitretação podem-se citar o aumento da dureza, da resistência ao desgaste, da resistência à fadiga e da resistência à corrosão.

A camada nitretada pode ser dividida em duas partes principais, camada de compostos e de difusão, como mostra a Figura 1. A camada de compostos, também conhecida como camada branca devido à cor que apresenta em revelação metalográfica, é constituída de nitretos de ferro do tipo $\varepsilon-F e 2-3(\mathrm{~N}, \mathrm{C})$ e/ou ' $\Upsilon$ '$\mathrm{Fe} 4(\mathrm{~N}, \mathrm{C})$. A camada de compostos possui composição química, estrutura cristalina e propriedades mecânicas bastante distintas do material base [2]. Diferentemente dos aços, a camada branca possui alta dureza, baixa tenacidade, baixos coeficientes de condutividade elétrica e de transferência de calor e alta resistência à corrosão.

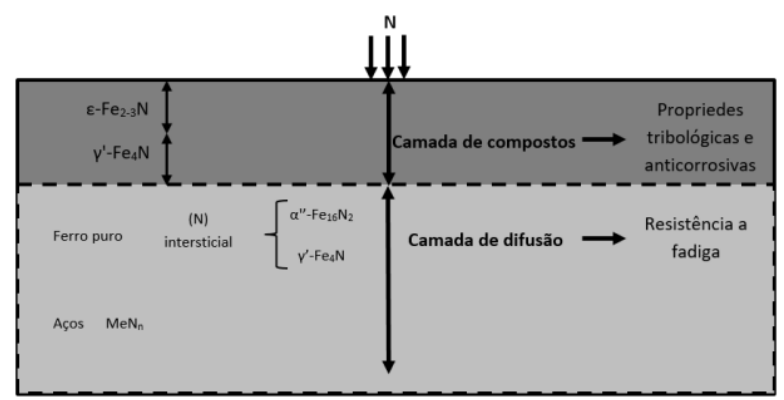

Figura 1: Esquematização da secção transversal da região nitretada de uma amostra ferrítica mostrando a camada de compostos e camada de difusão com seus possíveis constituintes [2].

Na nitretação gasosa, uma certa atividade de nitrogênio (ou carbono) é mantida na superfície da amostra através da decomposição de $\mathrm{NH}_{3}$ (ou $\mathrm{CO}_{2}$ ) proveniente de uma mistura gasosa de $\mathrm{NH}_{3}\left(/ \mathrm{CO}_{2}\right) / \mathrm{H}_{2}$. Assim, dependendo das pressões parciais dos gases e da temperatura, uma concentração constante na superfície da amostra é mantida [3]. Quando a atividade de nitrogênio é alta o suficiente, inicia-se a nucleação de $\gamma^{\prime}-\mathrm{Fe}_{4} \mathrm{~N}$ e $\varepsilon-\mathrm{Fe}_{2-3} \mathrm{~N}$ na superfície e posteriormente formação da camada branca. Apesar de $\gamma^{\prime}$ ser termicamente mais estável, Lightfoot e Jack [4] mostram que o nitreto do tipo $\varepsilon$ pode se formar antes de $\gamma^{\prime}$ dependendo do potencial de nitrogênio.

A presença de elementos de liga fortes formadores de (carbo-) nitretos neste aço faz com que ele tenha uma ótima resposta ao processo de nitretação e nitrocarbonetação, como dureza elevada e resistência ao desgaste e à fadiga $[5,6]$ mesmo que já possua boas propriedades mecânicas após tratamento térmico convencional.

Este trabalho se justifica pela avaliação de parâmetros de nitretação que serão futuramente utilizados na aplicação do método de difração de raios-x durante a nitretação in-situ. Além disso, poucos estudos foram realizados sobre nitretação gasosa em que o controle do processo é realimentado e utiliza sensores de potencial de nitrogênio e de carbono com os parâmetros aqui empregados.

Neste estudo, amostras de aço AISI 4140 foram nitretadas e caracterizadas quanto à composição química, espessura de camada, microestrutura, dureza, composição de fases e resistência ao desgaste para avaliar a resposta ao tratamento de nitretação gasosa do aço AISI 4140, em termos metalúrgicos, químicos e tribológicos.

\section{MATERIAIS E MÉTODOS}

As amostras sujeitas a este estudo foram fabricadas a partir de barras de aço laminadas e trefiladas do aço AISI 4140. A sua composição química foi analisada por espectroscopia de emissão óptica de descarga incandescente (Glow Discharge Optical Emission Spectroscopy- GDOES) e está demonstrada na Tabela 1. As amostras tiveram dimensões finais de $25 \mathrm{~mm}$ de diâmetro e espessura de $5 \mathrm{~mm}$. 
Tabela 1: Composição química do aço AISI 4140.

\begin{tabular}{c|c|c|c|c|c|c|c|c|c|c|c}
\hline ELEMENTO & $\mathbf{C}$ & $\mathbf{S i}$ & $\mathbf{M n}$ & $\mathbf{C r}$ & $\mathbf{M o}$ & $\mathbf{N i}$ & $\mathbf{C u}$ & $\mathbf{N}$ & $\mathbf{V}$ & $\mathbf{P}$ & $\mathbf{S}$ \\
\hline$\%$ massa & 0,41 & 0,24 & 0,77 & 1,01 & 0,164 & 0,10 & 0,193 & 0,01 & 0,93 & 0,01 & 0,03 \\
\hline AISI $^{\mathrm{N}}$ & $0,37-0,44$ & $0,15-0,30$ & $0,65-1,10$ & $0,75-1,20$ & $0,15-0,25$ & $\ldots$ & $\ldots$ & $\ldots$ & $\ldots$ & $\begin{array}{c}0,035 \\
\text { (máx.) }\end{array}$ & $\begin{array}{c}0,040 \\
\text { (máx.) }\end{array}$ \\
\hline
\end{tabular}

$\mathrm{N}$ - Valores de referência da norma AISI para este aço.

As amostras foram temperadas em óleo após serem mantidas a $850{ }^{\circ} \mathrm{C}$ por vinte minutos. $\mathrm{O}$ revenimento ocorreu a $550{ }^{\circ} \mathrm{C}$ por duas horas. A dureza final das peças foi de $350 \mathrm{HV}$. A temperatura de revenido foi escolhida em $550{ }^{\circ} \mathrm{C}$ para evitar um revenimento significativo durante a nitretação.

A Figura 3 mostra a microestrutura do material após o tratamento térmico formada por martensita revenida. Após o tratamento térmico, as duas faces das amostras foram retificadas. A face da amostra destinada às análises foi lapidada e polida. No processo de lapidação foi usada uma suspensão com diamante de $6 \mu \mathrm{m}$ e no polimento, uma suspensão com $3 \mu \mathrm{m}$. Após o polimento as amostras foram limpas em banho ultrassônico com solução alcalina, enxaguadas com água destilada e secas com jato de nitrogênio pressurizado.

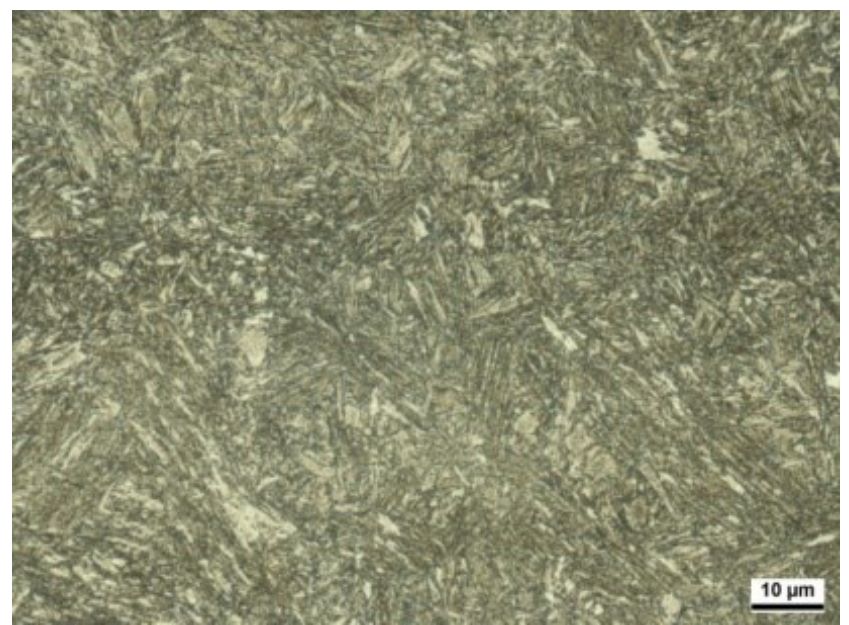

Figura 2: Microestrutura do aço AISI 4140 após têmpera e revenimento. Revelação com nital 3\% alc.

\subsection{Tratamentos Termoquímicos}

A Tabela 2 apresenta os diferentes parâmetros utilizados nos tratamentos de nitretação e nitrocarbonetação, bem como a nomenclatura das amostras que seguiu os potenciais de nitrogênio e carbono, bem como tempo. O equipamento utilizado para a realização das nitretações e da nitrocarbonetação é mostrado, Figura 3, é um forno de retorta para tratamentos termoquímicos com capacidade de 400 litros com dimensões de Ø600 x 700 $\mathrm{mm}$, temperatura máxima de $830^{\circ} \mathrm{C}$, recirculação, material da carcaça em aço DIN X15CrNiSi25-21, sensores de $\mathrm{O}_{2}, \mathrm{CO}_{2}$ e $\mathrm{H}_{2}$ e analisadores de $\mathrm{NH}_{3}$. $\mathrm{O}$ controle do processo foi através do potencial de nitretação e carbonetação a partir de pressões parciais dos gases na saída do forno conforme equações (1) e (2).

$$
\begin{aligned}
& K_{N}=p\left(\mathrm{NH}_{3}\right) / p\left(\mathrm{H}_{2}\right)^{3 / 2} \\
& K_{c}^{b}=p(\mathrm{CO})^{2} / p\left(\mathrm{CO}_{2}\right)
\end{aligned}
$$

onde $K_{N}$ é o potencial de nitretação, em bar1/2, p é pressão parcial dos gases, em bar, $K_{c}^{b}$ é o potencial de carbonetação, em bar. 
Tabela 2: Definição dos parâmetros de tratamentos térmicos.

\begin{tabular}{c|c|c|c|c|c|c|c}
\hline TRATAMENTO & $\mathbf{N 1 - 2 H}$ & $\mathbf{N 1 - 4 H}$ & $\mathbf{N 1 - 6 H}$ & $\mathbf{N 2 - 2 H}$ & $\mathbf{N 2 - 4 H}$ & $\mathbf{N 2 - 6 H}$ & $\mathbf{N C}-6 \mathbf{H}$ \\
\hline TEMPO (h) & 2 & 4 & 6 & 2 & 4 & 6 & 6 \\
\hline$K_{N}$ & 0,6 & 0,6 & 0,6 & 2,0 & 2,0 & 2,0 & 2,0 \\
\hline$K_{c}^{0}$ & - & - & - & - & - & - & 1,0 \\
\hline
\end{tabular}

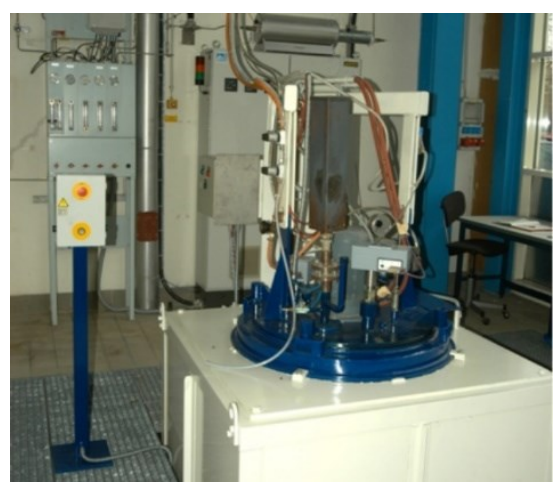

Figura 3: Forno de retorta para tratamentos termoquímicos

Os tratamentos consistiram em três etapas: aquecimento, manutenção e resfriamento. As etapas de aquecimento e resfriamento foram as mesmas para todos os tratamentos. Tanto o aquecimento quanto o resfriamento foram executados a uma taxa de $10{ }^{\circ} \mathrm{C} / \mathrm{min}$. Nestas etapas, foi empregado um fluxo de 1000 $\mathrm{ml} / \mathrm{min}$ de $\mathrm{N}_{2}$. A etapa de manutenção ocorreu à temperatura de $550^{\circ} \mathrm{C}$ para todas as amostras.

\subsection{Análise da Composição de Fases por Difração de Raios-X}

A determinação de presença de fases nas amostras foi realizada por um difratômetro D8 e um detector sensitivo de posição Vantec-1 Bruker-AXS. Para as medições, radiação Co-K $\alpha_{1}$ foi produzida por ânodo rotativo com voltagem de $35 \mathrm{kV}$ e corrente de $40 \mathrm{~mA}$. As medições foram feitas por modo de escaneamento contínuo com uma janela do detector de $5^{\circ}$. A faixa de medição em $2 \theta$ foi de $55^{\circ}$ a $156^{\circ}$ com uma velocidade de $0,1^{\circ}$ por segundo.

\subsection{Análise Metalográfica}

A fim de revelar a microestrutura das amostras e revelar adequadamente a camada branca e de difusão, as amostras foram cortadas para obtenção de uma seção transversal. Para preservar a estrutura da seção transversal a ser analisada, foi utilizado um equipamento de corte cut-off com o qual foram aplicados movimentos lentos de avanço e recuo e fluido lubrificante em abundância. As amostras foram embutidas em baquelite e foram lixadas sequencialmente até lixa \#1200 e, em seguida, polidas com uma suspensão de diamante de 1 $\mu \mathrm{m}$. Para revelar a microestrutura, a seção transversal foi atacada com reagente nital (concentração de $3 \%$ em álcool). O tempo de ataque foi de aproximadamente $15 \mathrm{~s}$, variando de amostra para amostra. Esta variação no tempo se dá devido ao contraste que cada uma das amostras revela dependendo da quantidade de cada fase presente. Devido à camada branca não ter uma espessura constante ao longo da superfície da amostra, a medição da sua espessura foi realizada através de medição da dez pontos em cada amostra e calculando sua média.

\subsection{Medições de Microdureza}

Os perfis de microdureza e a microdureza superficial foram obtidos pelo método Vickers com carga de $0,5 \mathrm{~kg}$ aplicada por 15 segundos. Esta carga produz uma indentação suficientemente pequena para tornar possível construir um bom perfil e ainda manter as diagonais da indentação adequadas para serem medidas. Para obter a dureza de superfície, foram feitas cinco indentações perpendicularmente à face de análise da amostra e foram obtidos valores médios representativos das amostras. Segundo a norma DIN 50190/3, o final da camada nitretada efetiva em função da profundidade é definida quando o aumento de dureza é na ordem de $50 \mathrm{HV}$ em relação a dureza de núcleo. 


\subsection{Determinação de Composição Química}

O perfil de composição química foi obtido através de Espectroscopia de Emissão Óptica de Descarga Incandescente (GDOES), que prevê uma rápida análise da composição atômica de sólidos tanto condutores como não-condutores. Este método determina a composição química em massa do material em função da profundidade partindo de uma profundidade em torno de $0,1 \mu \mathrm{m}$ até aproximadamente $50 \mu \mathrm{m}$.

\subsection{Ensaio de Desgaste Pino-Sobre-Disco}

Para caracterizar o coeficiente de atrito e a resistência ao desgaste das amostradas nitretadas foi realizado o ensaio pino-sobre-disco. O equipamento utilizado, mostrado na Figura 4, é da marca Wazau com torque máximo de $1 \mathrm{Nm}$ e força máxima de $100 \mathrm{~N}$. A velocidade tangencial foi de $0,1 \mathrm{~m} / \mathrm{s}$, raio de $7,5 \mathrm{~mm}$ e a força aplicada foi de $10 \mathrm{~N}$. Como discos foram utilizadas as amostras e como pino esferas de alumina comercialmente pura com diâmetro de $10 \mathrm{~mm}$. Estas esferas foram fixadas, de forma que houve apenas deslizamento entre pino e disco. $\mathrm{O}$ ensaio foi realizado à seco e à temperatura de $25^{\circ} \mathrm{C}$ e a umidade relativa do ambiente foi mantida em $30 \%$.

Foi selecionada uma amostra do tratamento N2-6H e feito dois ensaios, um deles com uma distância percorrida de $100 \mathrm{~m}$ e outra com $400 \mathrm{~m}$. Esta amostra foi escolhida por ter a maior espessura de camada branca e espera-se ter maior benefício para a resistência ao desgaste, em comparação às amostras com menor camada branca. Para fins de comparação, também foi realizado o ensaio em uma amostra não nitretada (somente temperada e revenida) com uma distância percorrida de $100 \mathrm{~m}$.

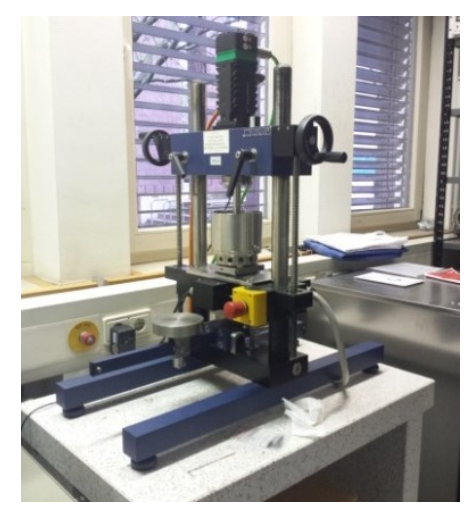

Figura 4: Equipamento para realização de ensaio pino-sobre-disco.

\section{RESULTADOS}

\subsection{Análises Metalográficas}

As metalografias das amostras N1-6H, N2-2H, N2-4H, N2-6H e NC-6H são mostrados na Figura 5. A espessura da camada branca destas amostras, bem como a camada de poros medida com base nas imagens da Figura 5 estão na Tabela 3. A camada branca se revelou muito menor no tratamento N1-6H que no N2-2H mesmo com o primeiro tendo o tempo de tratamento três vezes maior que o segundo tratamento, conforme Tabela 3. Isto indica que o potencial de nitretação teve maior influência sobre o tamanho da camada branca do que o tempo. É possível observar na porção superior da camada branca das amostras da Figura 5 que há a presença de poros. Estes poros enfraquecem a camada, tornando-a menos densa e mais frágil e não são industrialmente desejáveis. No entanto para situações de contato mecânico envolvendo lubrificação, a porosidade da camada pode ajudar na formação do filme de óleo.

No tratamento em condição N2 (Figura $5 \mathrm{~b}, 7 \mathrm{c}$ e 7d), observa-se o aumento da camada branca com o aumento do tempo de tratamento e o aumento da camada de poros seguindo a mesma tendência. A decomposição dos nitretos e a recombinação de nitrogênio atômico para molecular (gasoso) são atribuídos como principais causadores da formação de poros [7]. A camada branca após o processo de nitrocarbonetação NC-6H é mostrado na Figura 5e. A camada branca formada com este tratamento tem dimensões muito semelhantes àquela obtida na condição N2-4H. Isto indica que o potencial de carbonetação escolhido neste estudo não favorece o desenvolvimento da camada branca. 

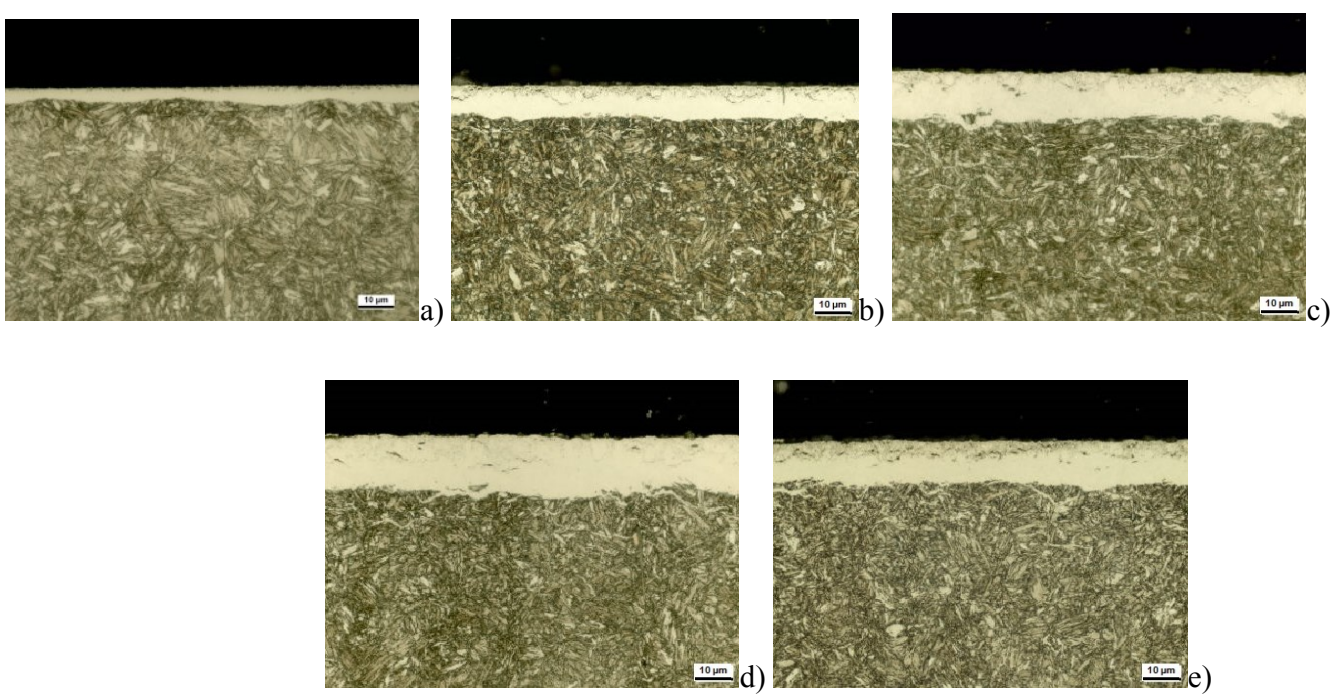

Figura 5: Metalografias da camada nitretada, com destaque para a camada branca, em AISI 4140 nas condições a) N1$6 \mathrm{H}$, b) N2-2H, c) N2-4H, d) N2-6H e e) NC-6H. Revelação com nital 3\% alc.

Tabela 3: Valores de espessuras de camada branca e poros das amostras analisadas por metalografia.

\begin{tabular}{ccccc}
\hline AMOSTRA & CAMADA BRANCA $(\boldsymbol{\mu M})$ & $\begin{array}{c}\text { CAMADA DE } \\
\text { POROS }(\mu \mathrm{M})\end{array}$ & $K_{N}$ & $K_{c}^{\pi}$ \\
\hline $\mathrm{N} 1-6 \mathrm{H}$ & $5,82 \pm 0,73$ & $0,92 \pm 0,03$ & 0,6 & - \\
$\mathrm{N} 2-2 \mathrm{H}$ & $8,95 \pm 0,57$ & $2,58 \pm 0,57$ & 2,0 & - \\
$\mathrm{N} 2-4 \mathrm{H}$ & $12,74 \pm 1,08$ & $3,23 \pm 1,10$ & 2,0 & - \\
$\mathrm{N} 2-6 \mathrm{H}$ & $16,14 \pm 1,09$ & $5,98 \pm 1,20$ & 2,0 & 1,0 \\
$\mathrm{NC}-6 \mathrm{H}$ & $12,74 \pm 1,07$ & $4,70 \pm 0,9$ & 2,0 & - \\
\hline
\end{tabular}

Enquanto que no tratamento N1-6H a camada branca alcançou aproximadamente $6 \mu \mathrm{m}$, os tratamentos N2-2H, N2-4H e N2-6H alcançaram cerca de 9, 13 e $16 \mu \mathrm{m}$, respectivamente. Entretanto, no caso do N1$6 \mathrm{H}$, a camada de poros foi de $16 \%$ da espessura da camada branca e no caso das nitretações com $K_{N}=2,0$, onde o potencial de nitretação é mais alto, a camada de poros é de $30-40 \%$ da camada branca.

\subsection{Difração de Raios-x}

Uma amostra de cada um dos tratamentos realizados neste trabalho e também uma amostra não nitretada foram analisadas por Difração de Raios-X (DRX). Os difratogramas obtidos são mostrados na Figura 6. É importante notar que na amostra não nitretada os picos de difração que se revelam são provenientes do Ferro- $\alpha$. Estes mesmos picos, quando presentes em amostras nitretadas, representam uma solução sólida de nitrogênio na ferrita.

À medida que a camada branca se desenvolve, os picos referentes ao substrato $(\alpha)$ se tornam menos intensos e podem inclusive não aparecer no difratograma. Isto ocorre devido à absorção da radiação pelas porções mais superficiais do material e, portanto, os raios difratados pelas porções mais internas são amenizados. 


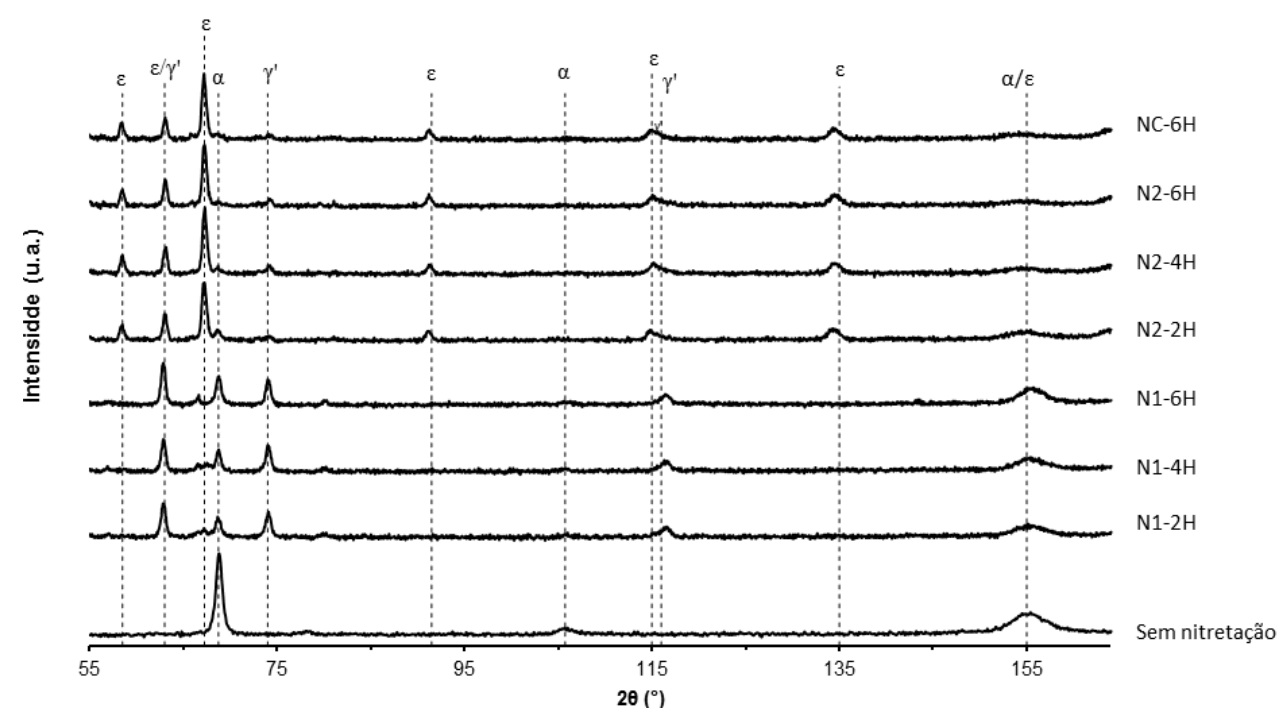

Figura 6: Espectro da difração de raios-x (DRX) das amostras nitretadas.

Pode-se observar nos espectros dos tratamentos N1-2H, N1-4H e N1-6H a presença das fases $\alpha$-Fe (substrato) e $\gamma^{\prime}$, indicando a formação de camada branca nestes tratamentos. Os picos referentes à fase $\gamma^{\prime}$ aumentam com o tempo de tratamento devido ao aumento de espessura da camada de nitretos $\gamma^{\prime}$. Há indícios de formação de $\varepsilon$ podendo indicar a nucleação deste nitreto sobre a camada de $\gamma^{\prime}$ mesmo com $K_{N}$ de 0,6 .

Nos tratamentos com $K_{N}$ de 2,0, a intensidade de $\gamma^{\prime}$ fica cada vez menor com o tempo de tratamento, ficando muito sutis. Temos que nos tratamentos N2-2H, N2-4H e N3-6H há um indício de que é formada uma camada branca multifásica. A fase $\alpha$ não é detectada nestas medições.

$\mathrm{O}$ difratograma referente à amostra $\mathrm{NC}-6 \mathrm{H}$ indicou majoritariamente a presença da fase $\varepsilon$ e, em menor intensidade, o que parece ser a formação a fase $\gamma^{\prime}$ no ângulo $2 \theta$ de $74^{\circ}$ (ângulo característico do pico de maior intensidade da fase $\gamma^{\prime}$ ). Os picos referentes à fase $\alpha$ praticamente inexistem devido à espessura da camada branca. Não são observadas novas fases no difratograma, como por exemplo, $\mathrm{Fe}_{3} \mathrm{C}$, devido à adição do potencial de carbono empregado neste trabalho. O aumento do percentual de carbono na matriz do ferro geralmente produz um aumento do teor de cementita e da precipitação de carbonetos. Como observado, o processo de nitrocarbonetação neste trabalho não eliminou a presença da fase $\gamma^{\prime}$.

\subsection{GDOES}

Os teores de nitrogênio como função da profundidade resultante nas amostras de cada um dos tratamentos, analisados por GDOES, foram reunidos na Figura 7. Fica evidente o aumento do teor de nitrogênio com 0 tempo de tratamento, bem como o potencial de nitretação. Comparando as nitretações, pode ser visto que o potencial de nitretação de 2,0 reduz significativamente o tempo requerido para atingir um determinado perfil em comparação com potencial de 0,6 . Ao observar as amostras N1-6H e N2-2H vemos que a segunda produziu uma camada branca $66 \%$ maior mesmo com tempo três vezes menor. 


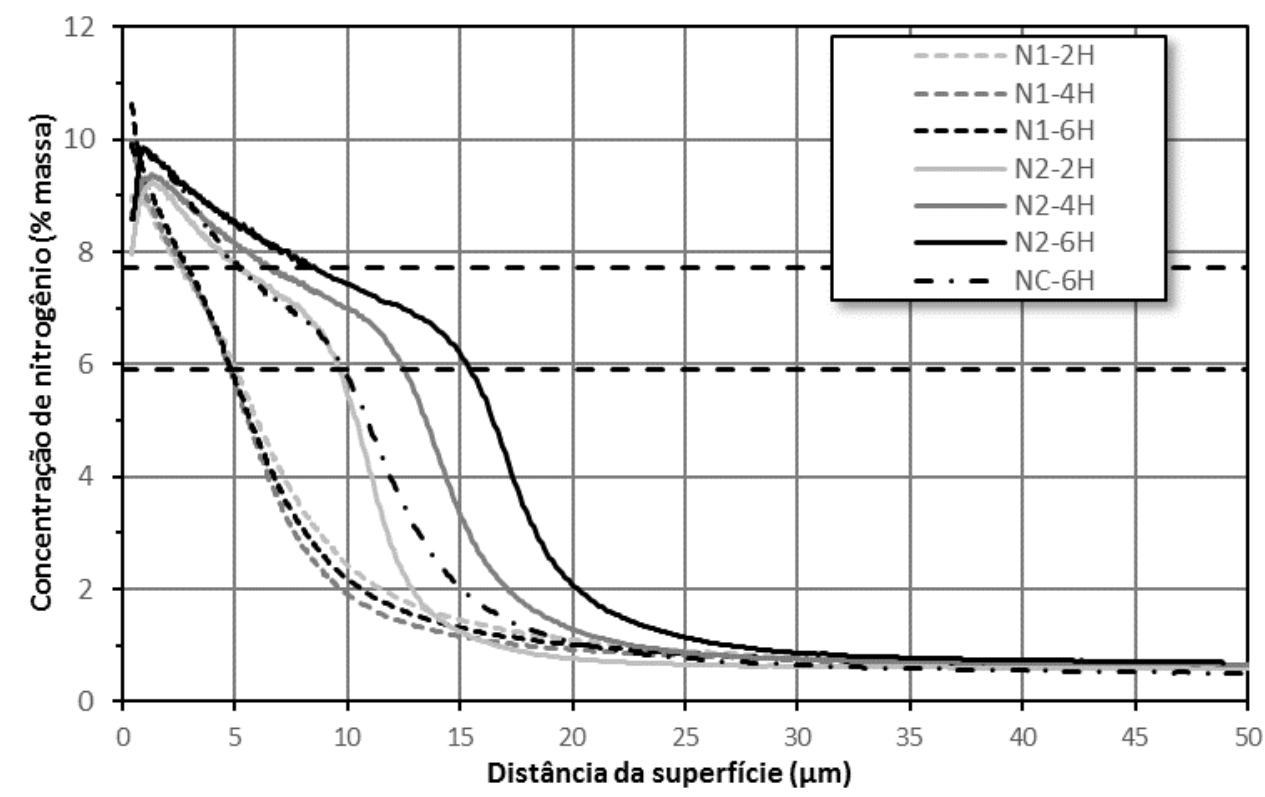

Figura 7: Perfil de nitrogênio nas amostras nitretadas obtido GDOES.

$\mathrm{Na}$ figura que representa o perfil de nitrogênio existem duas linhas horizontais intermitentes, uma superior e outra inferior. A linha intermitente inferior na Figura 7 indica em que profundidade está a interface entre a porção da camada branca que contém a fase $\gamma^{\prime}$ e a camada de difusão. Este dado também pode fornecer a espessura aproximada da camada branca. A linha intermitente superior também indica uma interface, agora entre as fases de nitretos $\gamma^{\prime}$ e $\varepsilon$.

Os tratamentos com $K_{N}=0,6($ amostras N1-2H, N1-4H e N1-6H) produziram perfis de nitrogênio que indicam a formação de camada branca bifásica muito estreita, cerca de $5 \mu \mathrm{m}$. Dentre estas três amostras, pode-se observar pouca diferença entre os perfis de nitrogênio e formação de camada branca com a variação do tempo. Considerando a formação da fase $\varepsilon$ de cerca de $3 \mu \mathrm{m}$, pode-se afirmar que a camada branca formada nestas amostras foi de $60 \%$ nitreto $\varepsilon$.

Ao se aumentar o potencial de nitrogênio para 2,0 (amostras N2-2H, N2-4H e N2-6H) observa-se uma dependência do tempo para a difusão do nitrogênio, como já demonstrado pelas metalografias da Figura 5. As curvas dos perfis de nitrogênio apresentam agora duas inclinações bem pronunciadas, tal como ocorre na nitrocarbonetação. Considerando a concentração de nitrogênio abaixo daquela que satisfaz a relação química $\mathrm{Fe}_{4} \mathrm{~N}$, é possível mensurar a camada branca com valores de 9,6, 12,5, 15,4 e 9,8 $\mu \mathrm{m}$ para as amostras $\mathrm{N} 2-2 \mathrm{H}$, $\mathrm{N} 2-4 \mathrm{H}, \mathrm{N} 2-6 \mathrm{H}$ e NC-6H, respectivamente. Tomando por base o tamanho da camada da fase $\varepsilon$ de $5,2,6,6$, 11,4 e $7,0 \mu \mathrm{m}$, obtém-se que nas duas primeiras amostras, a camada branca é formada por $53 \%$ de fase $\varepsilon$, na amostra $\mathrm{N} 2-6 \mathrm{H}, 74 \%$ de fase $\varepsilon$ e na amostra $\mathrm{NC}-6 \mathrm{H}, 71 \%$ de fase $\varepsilon$.

Com relação ao perfil de carbono medido demonstrado na Figura 8, pode-se ver que há a descarbonetação das amostras durante as nitretação. Os tratamentos com $K_{N}$ de 0,6 produziram picos de concentração de carbono de $0,2 \%$ em massa a uma profundidade de 3,5 $\mu \mathrm{m}$ com três diferentes tempos de tratamento. Nestes tratamentos, após o pico há um vale de concentração deste elemento que decresce para $0,06 \%$ em massa na profundidade de $15 \mu \mathrm{m}$ (dentro da camada de difusão) e então cresce até convergir para o teor de carbono original do material. A profundidade de descarbonetação está além da faixa medida $(50 \mu \mathrm{m})$.

Nos tratamentos com $K_{N}$ mais elevado $(2,0)$, a descarbonetação foi menor, como pode ser visto na Figura 8 . Também há a presença de picos e vales de concentração de carbono com picos variando $0,55 \%$ para $0,85 \%$ em massa, dependendo do tempo de tratamento (2, 4 ou 6 horas). 


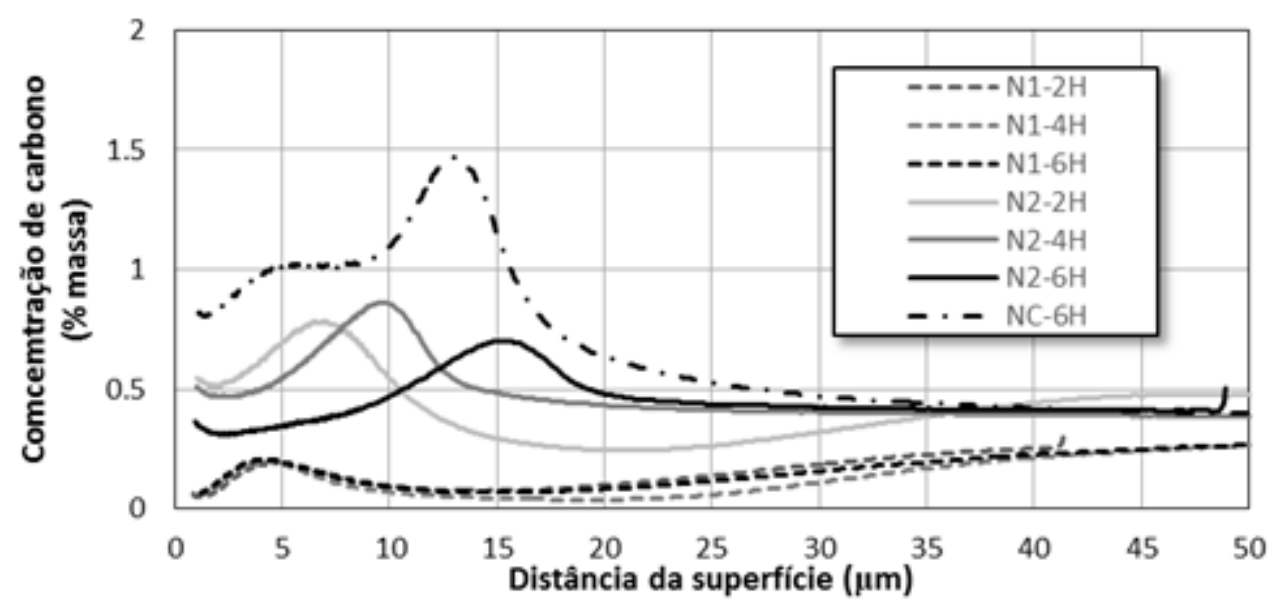

Figura 8: Análise do perfil de carbono por meio de GDOS para o aço AISI 4140.

\subsection{Microdureza}

O perfil de microdureza das amostras nitretadas está mostrado na Figura 9, executado com Vickers com carga de $0,5 \mathrm{~kg}$, mostra a profundidade da camada em função do tratamento. A região da camada de difusão tem, sob revelação metalográfica, um aspecto mais escuro do que o núcleo do material devido aos nitretos e carbonetos precipitados. Entretanto não é possível determinar visualmente a espessura da camada nitretada total porque o limite onde não há mais a formação de nitretos e carbonetos não é bem estabelecida e por isso vêm a necessidade de utilizar o perfil de dureza para determinar a camada nitretada.

A profundidade de camada, obtida por perfil de dureza e de acordo com norma DIN 50190/3 está mostrada na Tabela 4. A dureza da camada de difusão na região mais superficial se mantém constante, dentro de um pequeno desvio, para todas as amostras sob N2 e NC. A dureza superficial alcançada, medida com HV0,05, após os tratamentos N2-2H, N2-4H, N2-6H e NC-6H estão exibidos na Tabela 4. Esta tabela também compara estes os valores de dureza com a espessura de camada total e de camada branca.
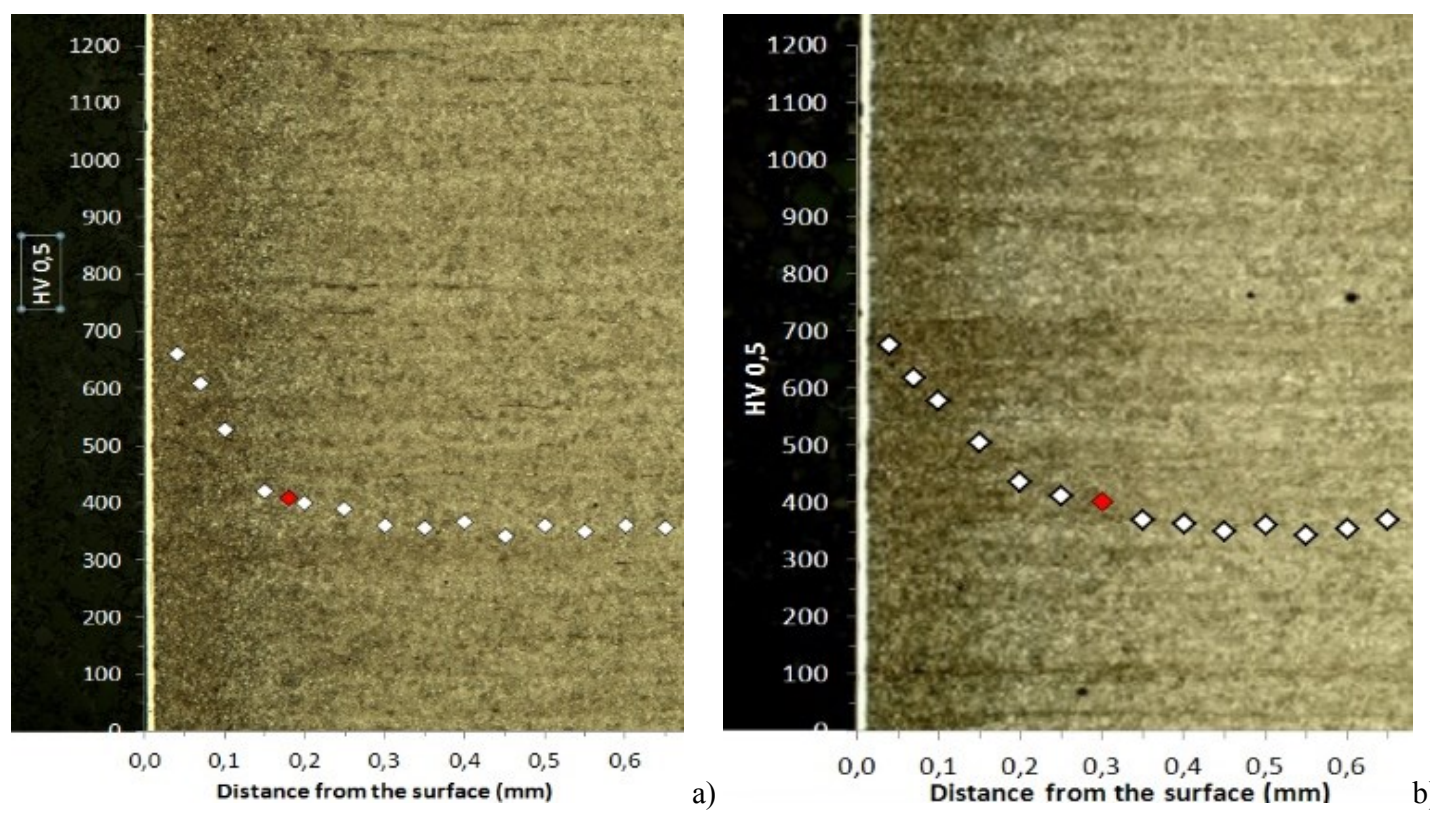

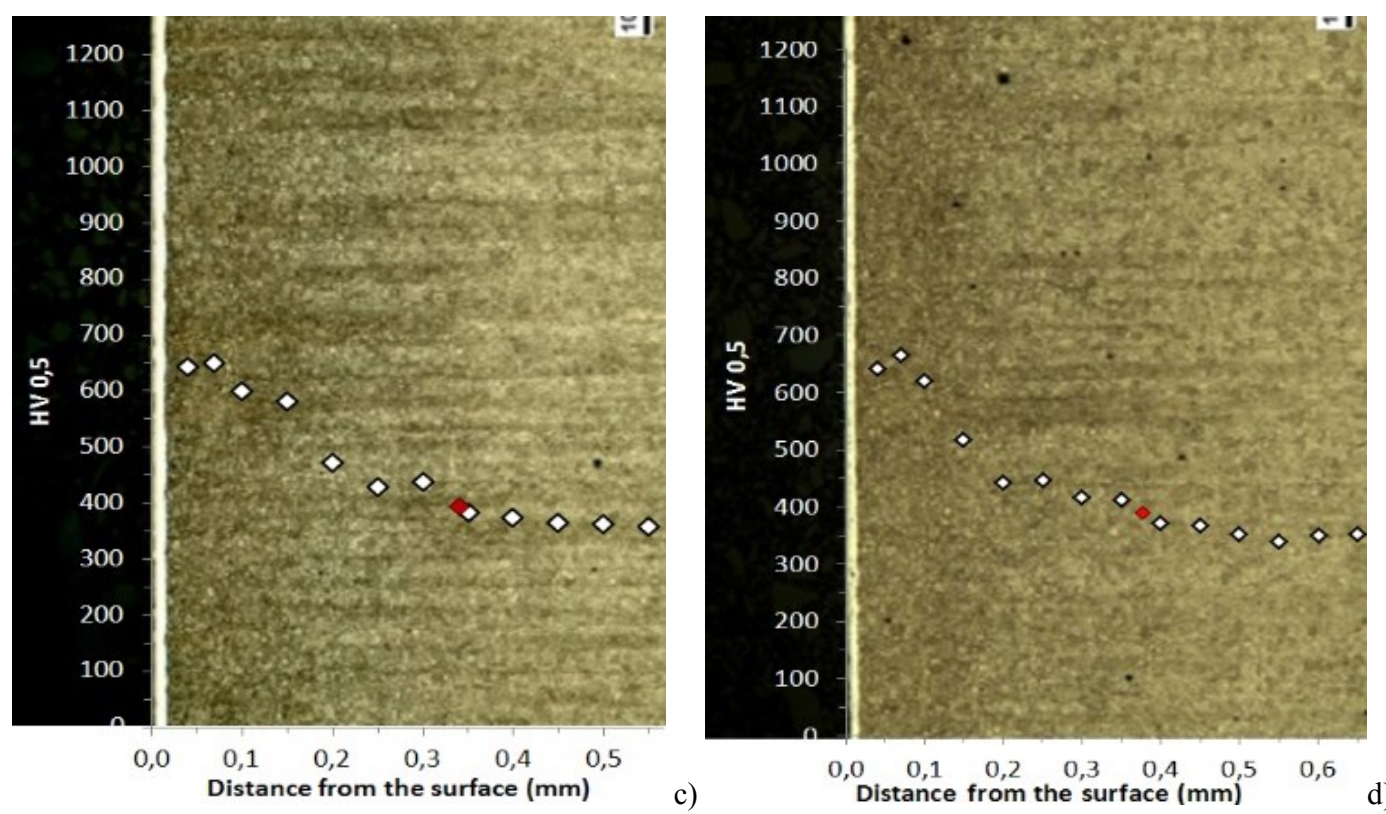

Figura 9: Perfil de dureza e metalografia do aço 4140 nitretado com as condições a) N2-2H, b) N2-4H, c) N2-6H e d) NC-6H. Os pontos vermelhos indicam a profundidade de nitretação.

Tabela 4: Dureza superficial, espessura de camada e de camada branca das amostras.

\begin{tabular}{c|c|c|c}
\hline AMOSTRA & $\begin{array}{c}\text { DUREZA MÉDIA SUPERFICI- } \\
\text { AL (HV0,05)/DESVIO PA- } \\
\text { DRÃO }\end{array}$ & $\begin{array}{c}\text { ESPESSURA DA CAMADA } \\
\text { NITRETADA TOTAL }(\boldsymbol{\mu M})\end{array}$ & $\begin{array}{c}\text { ESPESSURA DA CAMADA } \\
\text { BRANCA }\end{array}$ \\
\hline $\mathrm{N} 2-2 \mathrm{H}$ & $728 \pm 34$ & 180 & $8,95 \pm 0,57$ \\
\hline $\mathrm{N} 2-4 \mathrm{H}$ & $639 \pm 27$ & 300 & $12,74 \pm 1,08$ \\
\hline $\mathrm{N} 2-6 \mathrm{H}$ & $567 \pm 26$ & 340 & $16,14 \pm 1,09$ \\
\hline $\mathrm{NC}-6 \mathrm{H}$ & $533 \pm 38$ & 380 & $12,74 \pm 1,07$ \\
\hline
\end{tabular}

\subsection{Ensaio Pino-Sobre-Disco}

A Figura 10 mostra os coeficientes de atrito obtidos durante o decorrer do ensaio pino-sobre-disco entre o pino de alumina e as amostras nitretadas e não-nitretadas. Os valores do coeficiente de atrito obtidos foi de 0.55 para a amostra sem tratamento e 0.8 para a amostra nitretada, valores esses confirmados no trabalho de Bressan e Comeli [10] e Almeida et al. [11] através de amostras de aço H13 nitretada a gás com formação de camada branca e pino de alumina.

$\mathrm{Na}$ amostra nitretada, observa-se um coeficiente de atrito muito baixo na Figura 10 nos primeiros 10 metros do ensaio. Em geral, quanto maior a dureza superficial de uma amostra, menor é a área de contato, mas a tensão de cisalhamento aumenta com o aumento de dureza dos materiais, por isso o coeficiente de atrito é maior em aços revestidos, por exemplo por processo PVD [12]. Como inicialmente o deslizamento ocorre sobre a camada de poros que tem alta rugosidade, nesta etapa o coeficiente de atrito tende a diminuir por causa da menor área de contato. Durante o ensaio as asperezas da superfície da amostra são removidas e o coeficiente de atrito começa a aumentar levemente devido ao aumento da área de contato ente o pino e o disco. A partir de um dado momento, a porção da camada branca com porosidade se quebra e a porção da camada branca sem poros é exposta ao pino de alumina e neste momento observamos o aumento brusco do coeficiente de atrito. Após $80 \mathrm{~m}$ de ensaio, o coeficiente de atrito se estabiliza em 0,8 na amostra nitretada. 


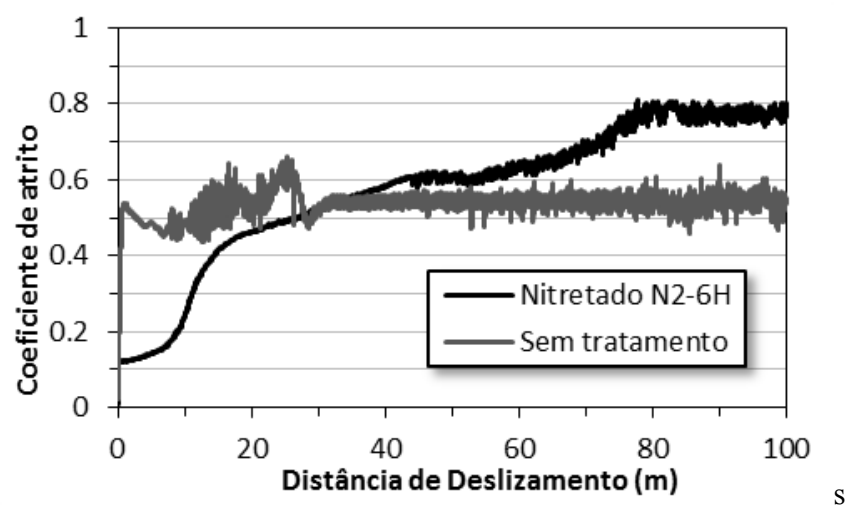

Figura 10: Coeficiente de atrito médio obtido no ensaio pino-sobre-disco em função da distância de deslizamento.
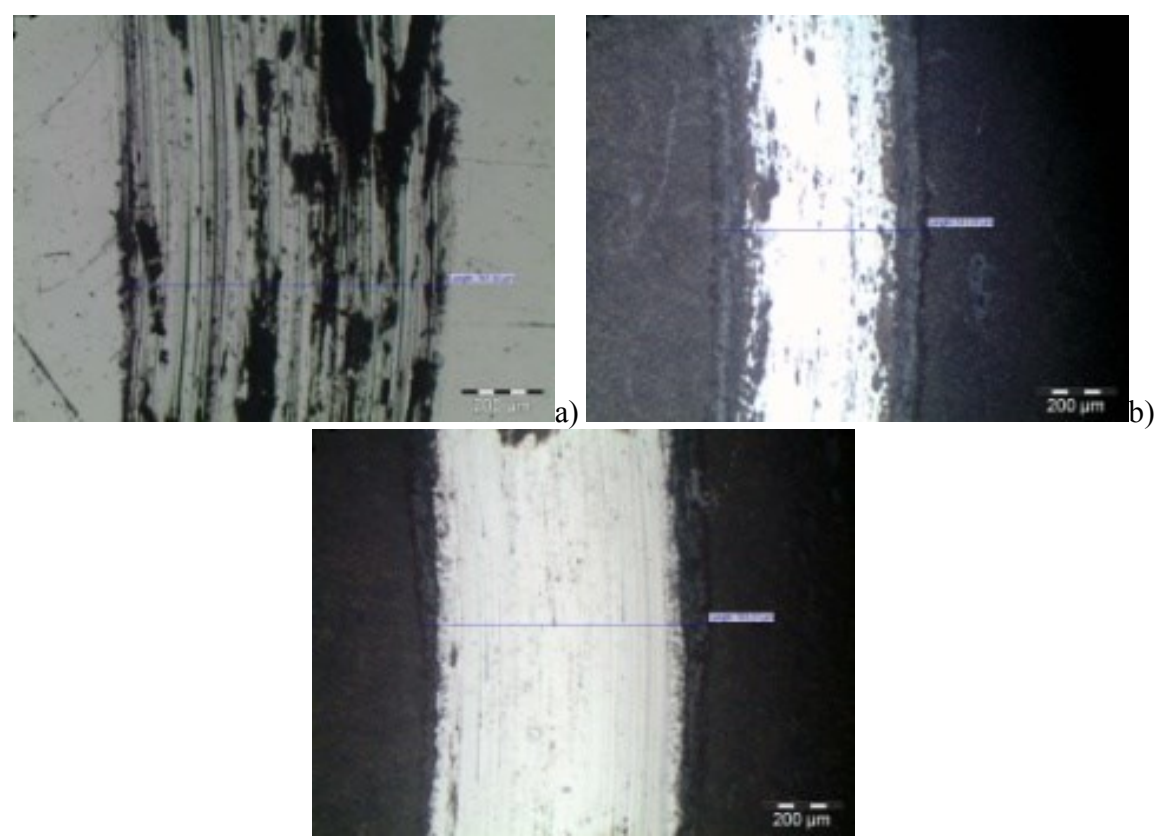

Figura 11: Trilhas de desgaste em amostra (a) não-nitretada após ensaio de $100 \mathrm{~m}$, (b) nitretada após ensaio de $100 \mathrm{~m}$ e (c) nitretada após ensaio de $400 \mathrm{~m}$.

O interior da amostra sem nitretação (Figura 11a) mostra altas deformações plásticas, presença de ris$\cos /$ sulcos paralelos à direção de deslizamento, indicando desgaste abrasivo. Esta abrasão pode ter sido causada ou pelo pino de alumina com dureza muito maior ou pelas partículas de desgaste desassociadas da amostra que permaneceram na interface de contato, sofreram grandes deformações e, com isso, aumento de resistência. O desgaste por adesão também está presente, pois, é possível que o material da amostra tenha aderido à esfera e então material da esfera foi transferido para a amostra. A composição da esfera $\left(\mathrm{Al}_{2} \mathrm{O}_{3}\right)$, por sua vez, tem menos afinidade química com o material da amostra, o que reduz a adesão. Neste ensaio, a adesão foi promovida pela não utilização de lubrificante. Caso o teste fosse repetido utilizando um pino de aço ou outro material com afinidade ao aço, a adesão seria mais proeminente.

Nas Figuras $11 \mathrm{a}$ e $11 \mathrm{~b}$ pode ser visto as trilhas de desgaste das amostras nitretadas que passaram pelo ensaio com distância de 100 e $400 \mathrm{~m}$. Com a distância de 100 ainda há uma pequena quantidade de camada branca porosa não removida, enquanto que na amostra que percorreu $400 \mathrm{~m}$ de ensaio a camada branca não tem mais a camada de poros. É possível observar ainda a presença de riscos e sulcos na trilha de desgaste, devidos às partículas de material que soltaram da amostra e permaneceram na interface de contato do ensaio. Entretanto não há a presença de sinais de desgaste adesivo.

A Tabela 5 mostra A largura média das trilhas de desgaste das amostras após cada ensaio pino-sobredisco. Também é demonstrado o respectivo volume perdido pelos discos calculados com base na largura das trilhas. A amostra sem o tratamento de nitretação apresenta uma trilha mais larga que a amostra nitretada após a mesma distância percorrida de 100m, conforme Figuras 11a e 11b, respectivamente. Isto mostra que há uma melhora na resistência ao desgaste abrasivo após a nitretação gasosa do aço AISI 4140. Para a distân- 
cia de $100 \mathrm{~m}$ o volume perdido numa amostra não-nitretada é de $0,3093 \mathrm{~mm}^{3}$ e numa amostra nitretada é de $0,1208 \mathrm{~mm}^{3}$. Com isso, podemos dizer que o volume removido nestas condições numa amostra nitretada é $61 \%$ menor do que numa amostra não-nitretada. Para um valor de volume removido semelhante, $0,2840 \mathrm{~mm}^{3}$, a distância percorrida numa amostra nitretada sob ensaio pino-sobre-disco teve que ser de $400 \mathrm{~m}$, ou, quatro vezes maior.

Tabela 5: Volume perdido pelas amostras nitretada e não nitretada no ensaio pino-sobre-disco.

\begin{tabular}{c|c|c|c}
\hline AMOSTRA & DISTÂNCIA $(\mathbf{m})$ & LARGURA DA TRILHA $(\mathbf{m m})$ & VOLUME PERDIDO $\left(\mathbf{m m}^{\mathbf{3}}\right)$ \\
\hline Nitretada & 100 & 0,5356 & 0,1208 \\
\hline Nitretada & 400 & 0,7121 & 0,2840 \\
\hline Não-nitretada & 100 & 0,7326 & 0,3093 \\
\hline
\end{tabular}

\section{DISCUSSÃO}

Nas análises metalográficas apresentadas na Figura 5 é possível observar a formação de uma grande quantidade de nitretos precipitados. A microestrutura da camada de difusão apresenta uma similaridade muito grande em todas as amostras analisadas, mesmo variando parâmetros do processo como tempo, potencial de nitretação e carbonetação. O efeito de cada um destes parâmetros, neste aço, está mais relacionado com a influência sobre a espessura da camada nitretada. Após a formação da camada branca, a camada de difusão tem seu crescimento desacelerado em função da grande densidade que atua como uma barreira para o processo difusional. Para se obter uma camada de difusão espessa por nitretação gasosa, é necessária uma atmosfera com potencial de nitretação baixo o suficiente apenas para retardar ou inibir a formação de camada branca, também chamado em inglês de treshold, e realizado por um tempo na ordem de dezenas de horas [8].

Isto indica que um potencial de nitretação e, consequentemente, maiores pressões parciais de $\mathrm{H}_{2}$ são de alguma forma responsáveis pela formação de poros. Na nitrocarbonetação NC-6H, onde o potencial de nitretação é de 2,0, a camada de poros alcançou $37 \%$ da camada branca indicando uma tendência similar à formação de poros comparável à nitretação das amostras com $K_{N}$ de 2,0, onde a carbonetação combinada com tal potencial de nitretação não é favorável à formação de uma camada branca com a ausência de poros.

As análises de DRX revelam que em todas as condições de tratamento há a presença da fase de nitretos e carbonitretos $\varepsilon$ na camada branca. A fase de nitretos $\gamma^{\prime}$ também está presente, mas devido a sua formação ser abaixo da fase $\varepsilon$, quanto mais espessa for a camada branca, menores serão os picos de difração referentes a $\gamma^{\prime}$. A fase $\gamma^{\prime}$ também é precipitada em contorno de grão na camada de difusão, por isso, a presença de picos de difração apenas da fase $\gamma^{\prime}$ não comprova a presença de camada branca, sendo necessária a análise microestrutural [13].

É interessante notar que os picos de $\alpha$-Fe nas amostras nitretadas se encontram levemente deslocados para a região de menor ângulo $2 \theta$ com relação à amostra sem nitretação. Isto indica um parâmetro de rede, na condição Bragg-Bentano, maior do que aquele medido na amostra não-nitretada, segundo a Lei de Bragg. $\mathrm{O}$ aumento do parâmetro de rede é proveniente da presença de nitrogênio intersticial e, após a saturação do elemento, pela formação de nitretos e que geram um aumento de tensão residual compressiva na camada nitretada. Esse aumento no nível de tensões residuais na superfície de um componente mecânico melhora a sua vida em fadiga [6][14].

Com base nos perfis de nitrogênio da Figura 7, é mostrado que na nitretação com $K_{N}=2,0$, a fase $\gamma^{\prime}$ se desenvolve até certo momento, tendo seu tamanho limitado a 5,9 $\mu \mathrm{m}$, enquanto que a fase $\varepsilon$ continua crescendo à medida que o tempo de tratamento aumento. Nota-se o aumento acentuado na proporção de nitretos $\varepsilon$ na camada nitrocarbonetada, mas não se atingiu uma camada branca monofásica.

Nas nitretações com potencial de nitretação maior e também na nitrocarbonetação observa-se um aumento do potencial de nitrogênio seguido duas inclinações negativas distintas do perfil de nitrogênio. Com maior potencial de nitrogênio, a dissociação da amônia é maior e a taxa de difusão de nitrogênio é alta, o que por dedução traria uma concentração maior deste elemento na superfície do material. Porém, o estudo de Haase et al. [15] mostrou que a combinação de alto potencial de nitretação e determinados métodos de preparação superficial induzem ao comportamento observado na Figura 7 para as amostras N2-2H, N2-4H, N2-6H e NC-6H. A inclinação negativa mais superficial, menor e com maior quantidade de nitrogênio, está indicando a presença da camada branca. Após esta primeira camada, o equilíbrio na concentração deste elemento faz com que ele se difunda mais rapidamente em direção ao núcleo, como mostrado pelo aumento da inclinação 
das respectivas curvas da Figura 7.

A adição do potencial de carbonetação, no tratamento NC-6H, resultou num perfil de nitrogênio semelhante ao tratamento N2-4H, tanto na região da camada branca como na porção da camada difusão observada na Figura 7. A adição de carbono não foi benéfica para o crescimento da camada nitretada quando junto ao potencial de nitretação mais alto. Na comparação entre os tratamentos NC-6H e N2-6H, a nitretação atingiu uma camada branca $24 \%$ maior. Um resultado semelhante foi encontrado no trabalho de Skonieski et al [9] (2013), que compararam nitretação e nitrocarbonetação a plasma sobre o mesmo material base, mantendo todos os parâmetros iguais, mas adicionando pequenos teores de $\mathrm{CH}_{4}$. Como resultado, a camada branca formada na amostra nitrocarbonetadas foi de $4 \mu \mathrm{m}$ enquanto que na amostra nitretada foi de $10 \mu \mathrm{m}$ após 6 horas de tratamento. Também foi reportado por estes autores que a dureza superficial do material nitrocarbonetadas foi em média $1277 \mathrm{HV} 0,025$ enquanto que na amostra nitretada a dureza média foi de $1159 \mathrm{HV} 0,025$. A maior dureza na camada branca de um aço carbonitretado é o fato de ser formada uma maior quantidade de (ou exclusivamente) fase $\varepsilon$, que é mais dura que a fase $\gamma^{\prime}$.

O aço AISI 4140, como mostra a Figura 7, apresenta uma quantidade de nitrogênio de cerca de 1\% abaixo da camada branca, dentro da camada nitretada independente do tratamento executado. Nos tratamentos $\mathrm{N} 1$, o teor de nitrogênio nesta faixa de profundidade foi um pouco menor, cerca de $0,8 \%$ em massa. Conforme estudo de Jack [16], isto é uma indicação de que o aço formou nitretos com seus elementos de liga, principalmente o manganês, além de molibdênio e cromo.

O perfil de carbono nas amostras, mostrado na Figura 8 , indica que há descarbonetação durante a nitretação gasosa. As nitretações com potencial de nitrogênio maior produziram uma camada branca considerável e também tiveram menos perda do elemento carbono. Com isso, mostra-se que a camada branca é uma barreira para a difusão de carbono.

O perfil de dureza das diferentes amostras mostra que mesmo com a formação de uma camada branca com mais de $10 \mu \mathrm{m}$, como mostrado na Tabela 3, a camada nitretada aumenta em função do tempo, ao contrário do que se espera que é um estacionamento do aumento de espessura de camada, pois a camada branca funciona como uma barreira para o processo difusional do nitrogênio. A dureza da zona de difusão, na região mais próxima à superfície possui valores similares para as quatro amostras analisadas de variando de 728 a 567 HV. Outros autores reportaram valores semelhantes para a camada de difusão nitretando a plasma [9] [13] e a gás [17] o mesmo material.

Os resultados de dureza superficial, encontrados na Tabela 4, confrontam o que é esperado para o valor de dureza em função do aumento da camada branca, que é um aumento de dureza com quanto maior o tempo de tratamento. Com a intensificação da formação de poros, a dureza da camada branca é comprometida e por isso há redução no seu valor, fato este que pode ser confirmado por Skonieski et al. [9]. Na nitretação a plasma a camada de poros obtida foi muito pequena e assim, uma maior dureza superficial foi alcançada à medida que a espessura aumenta. Se por um lado temos a queda de dureza com a formação de poros, por outro temos que o aumento da espessura de camada branca diminui a porção da camada de difusão que é afetada pela indentação e deveria fazer com que a dureza medida fosse maior nas amostras com camada branca mais espessa.

Pode-se afirmar que a nitretação N2-6H foi eficiente em melhorar a resistência ao desgaste do aço AISI 4140 , pois o volume removido numa amostra nitretada no ensaio pino-sobre-disco foi $61 \%$ menor do que numa amostra não-nitretada, após percorridos 100m. Para efeitos de comparação, uma amostra nitretada percorreu $400 \mathrm{~m}$ para ter um valor de volume removido semelhante ao de uma amostra não nitretada que percorreu $100 \mathrm{~m}, 0,2840 \mathrm{~mm}^{3}$. Colocando de outra forma, uma amostra nitretada pode percorrer uma distância quatro vezes maior para ter o mesmo desgaste de uma amostra temperada.

\section{CONCLUSÕES}

Os resultados apresentados indicam que o aço AISI 4140 se mostra adequado para tratamentos de nitretação e nitrocarbonetação, uma vez que se verificou um ganho nas propriedades mecânicas e tribológicas da superfície deste aço.

Todas as condições de tratamento foram capazes de gerar significativo incremento da dureza superficial, elevando-a de $350 \mathrm{HV}$ no núcleo do material para valores em torno de $750 \mathrm{HV}$.

Um aumento no potencial de nitretação da atmosfera nitretantes levou a uma queda acentuada no tempo de formação da camada nitretada e espessura de camada branca. O perfil de propriedades da camada nitretada se mantém constante, variando apenas a sua profundidade e espessura de cada uma de suas, sob um mesmo potencial de nitretação. 
O potencial de nitrogênio de 0,6 foi suficiente para a formação de camada branca no aço AISI 4140. A espessura obtida após 6 horas de tratamento foi de $0,92 \mu \mathrm{m}$, medida através de metalografia. A análise por GDOES indica que a espessura nas amostras nitretadas com 2 e 4 horas tenham espessura de camada branca semelhante.

Foi observado a formação de poros na camada branca. Verificou-se que a camada de poros aumenta com a espessura da camada branca. A nitrocarbonetação aplicada neste trabalho não resultou em uma menor camada de poros, mas sim em um nível de porosidade semelhante aqueles encontrados nas nitretação. Foi confirmada a presença de uma camada branca bifásica na nitrocarbonetação.

A difração de raios-x mostrou que há formação de camada branca nas nitretações e também na nitrocarbonetação formada principalmente por nitretos $\varepsilon$, usando potencial de nitrogênio 2,0 e na nitrocarbonetação. Na nitretação com menor potencial, o nitreto $\gamma^{\prime}$ foi predominante.

Os ensaios de desgaste pino-sobre-disco mostraram que a camada nitretada aumenta significativamente a resistência ao desgaste, devido ao aumento de dureza observado. O mecanismo de desgaste é alterado pela presença da camada nitretada de desgaste abrasivo e adesivo para desgaste abrasivo. O coeficiente de atrito entre a amostra e o pino de alumina é mais baixo na amostra nitretada no início do ensaio devido a rugosidade da camada do que a amostra sem nitretação, cerca de 0,55 . Mas após as asperezas serem removidas e o ensaio se estabilizar, o coeficiente de atrito aumenta para 0,8 .

\section{AGRADECIMENTOS}

Os autores agradecem ao Stiftung Institut für Werkstofftechnik (IWT-Bremen) pela realização dos experimentos e ao Grupo de Engenharia de Superfícies do Laboratório de Transformação Mecânica (GES/LdTM/UFRGS) e ao CNPq o apoio no âmbito do Processo 311348/2015-7, Produtividade em Pesquisa - PQ 2015.

\section{BIBLIOGRAFIA}

[1] MITTEMEIJER, E.J. "Fundamentals of nitriding and nitrocarburizing", In: DOSSETT, J., TOTTEN, G.E. ASM Handbook, v. 4A, Steel Heat Treating Fundamentals and Processes, ASM International, pp. 619-646, 2013.

[2] BRINKSMEIER, E., HOFFMANN, F., GLÄBE, R., et al., "Diamond Machinable Tool Steels by Novel Nitriding Processes". In: Fabrication of Complex Optical Components, LNPE, Springer-Verlag Berlim Heidelberg, pp. 67-83, 2013.

[3] SOMERS, M., Internal and external nitriding and nitrocarburizing of iron and iron-based alloys, Tese de D.S., Delft University of Technology, Delft, Holanda, 1989.

[4] LIGHTFOOT, J., JACK, D.H., "Kinetics of nitriding with and without compound layer formation", In: Proceedings of Heat Treatment'73, pp. 59-65, Londres, Reino Unido. 1973.

[5] PAN, J., HU, M., MAO, L., et al., "Mathematical model of controlled nitriding and its application", In: Proceedings of Heat Treatment Shanghai '83, p. 1.11, Shanghai, China, 1984.

[6] GENEL, K., DEMIRKOL, M., CAPA, M., "Effect of ion nitriding on fatigue behaviour of AISI 4140 steel”, Materials Science and Engineering, v. A279, pp. 207-216, 2000.

[7] HOFFMANN, F., KUNST, H., KLÜMPER-WESTKAMP, H., et al., "Stand der Kenntnisse über die Porenentstehung beim Nitrieren und Nitrocarburieren", In: Proceeding of The 1th European conference Nitriding and Nitrocarburising, pp. 105-113, Darmstadt, Alemanha, 1991.

[8] GRESSMANN, T., LEINEWEBER, A., MITTEMEIJER, E.J., et al., "X-ray diffraction analysis of an $\varepsilon / \gamma$ ' ironnitride compound double layer", Zeitschrift für Kristallographie, n. 26, pp. 223-228, 2007.

[9] SKONIESKI, A.F.O., SANTOS, G.R., HIRSCH, T.K., et al., "Metallurgical Response of an AISI 4140 Steel to Different Plasma Nitriding Gas Mixtures", Materials Research, n. 16, v. 4, pp. 884-890, 2013.

[10] BRESSAN, J.D., COMELI F.W., "Estudo da resistência ao desgaste de aço AISI 422 tratado termicamente, nitretado e com revestimentos aspergidos de carboneto de cromo-níquel", In: Anais do $4^{\circ}$ Congresso Brasileiro de Engenharia de Fabricação, Águas de São Pedro, São Paulo, 2007.

[11] ALMEIDA, E.A.S., MILAN, J.C.G., COSTA, C.E., "Acquired Properties Comparison of Solid Nitriding, Gas Nitriding and Plasma Nitriding in Tool Steels", Materials Research, v. 18, n. 1, pp. 27-35, 2015. 
[12] HOLMBERG, K., MATTHEWS, A., Coatings Tribology: Properties, Techniques and Applications in Surface Engineering, 2nd Edition, Elsevier, Oxford, 2009.

[13] ZAMBON, M.F., CASTELETTI, L.C., FERNANDES F.A.P., NASCENTE, P.A.P., "Influência da temperatura na nitretação iônica dos aços DIN16MnCr5, AISI-420 e SAE-4140", Revista Brasileira de Aplicações de Vácuo, v. 29, n. 2, pp. 77-80, 2010.

[14] LIMODIN, N., VERREMAN, Y., "Fatigue strength improvement of a 4140 steel by gas nitriding: Influence of notch severity", Materials Science and Engineering: A, v. 435-436, pp. 460-467, nov. 2006.

[15] HAASE, B., DONG, J., IRRETIER, O., BAUCKHAGE, K., "Composition of steel surfaces and its influence on the gas nitriding mechanism", In: Proceedings of the Tenth International Conference on Surface Modification Technologies, Singapore, 1996.

[16] JACK, K.H., "Nitriding”, In: Proceedings of Heat Treatment'73, pp. 59-65, Londres, Reino Unido. 1973. [17] LEITÃO, C.J., MEI, P.R., LIBARDI, R., "Efeitos da cementação e da nitretação no custo e na qualidade de engrenagens produzidas com aços ABNT 4140 e 8620", Tecnologia em Metalurgia, Materiais e Mineraçã , v. 9 , n. 3, pp. 257-263, jul.-set. 2012. 